\title{
Why do homosexual men continue to practise \\ unsafe sex? A critical review of a qualitative research paper
}

Continuing medical education

\author{
Kevin A Fenton, Robert Power
}

\section{Introduction}

Qualitative techniques using in depth questioning in individual interviews and focused group discussions are particularly suited to exploring the factors that influence behaviour. Qualitative researchers study phenomena and events in their natural settings, often interpreting them in terms of the subjective meanings attached by the individual. This approach is unique in its ability to provide a greater understanding of the full range of experiences and attitudes. In contrast with the deductive predominance of most quantitative research, qualitative research tends to be inductivethat is, uses empirical data to build up a picture and understanding of the phenomenon being researched. Indeed many of the computer packages that are now used for the analysis of qualitative data are based on the inductive framework which uses data to generate hypotheses and build theories-a "grounded theory" approach.

Qualitative techniques can also identify issues and concepts; clarify language and meaning; and explore perceptions, experiences, attitudes, and behaviour. With appropriate sample selection, these factors can be investigated in terms of differences and similarities between individuals, as well as addressing the complexities of individual experience. It is particularly appropriate for exploration of sensitive topics, the success of which depends on building rapport and gaining the confidence of the respondent.

Sexual health is perhaps one area where the complementary use of qualitative and quantitative research methods is best illustrated. Qualitative research has contributed greatly to our understanding of sexual behaviours and lifestyles, safer sex practice, and understanding

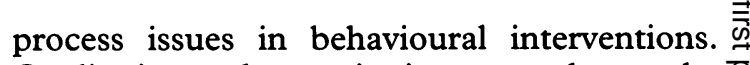
Qualitative and quantitative research may be used to investigate similar topics although each will address a different type of question. For example, in relation to sexual behaviour, a $\triangle$ quantitative study can determine the distribution and determinants of multiple sexual part- $\overrightarrow{0}$ nerships among a group of respondents. A qualitative approach, on the other hand, $\omega$ would be more appropriate to explore con- $\stackrel{\text { of }}{=}$ cepts surrounding choice of partners, nuances $\omega$ of behaviours, and sociocultural factors associ- ir ated with the adoption of this lifestyle.

In this article we illustrate how to critically review qualitative research findings using a 을 critical appraisal checklist which compiles a $\vec{O}$ number of key assessment criteria (see table 1). These criteria will be applied to an article which examines homosexual men's explanations for engaging in unprotected anal inter- 8 course. ${ }^{1}$ Each of the following sections relates. to the points obtained in the critical appraisal checklist.

\section{Does the article describe an important clinical problem addressed via a clearly formulated question?}

There can be little doubt that the study of sexual behaviour is crucial to our understanding of the epidemiology of HIV disease. Over the past 15 years, studies of homosexual and 3 bisexual men have shown marked changes in their sexual behaviour in response to the threat of HIV/AIDS. These have included a decline 0 in the number of sexual partners, a reduction in the frequency of unprotected acts of anal sex, and an increase in the use of condoms for penetrative $\operatorname{sex}^{23}$ In spite of this, there is growing evidence that a significant proportion

Table 1 Critical appraisal checklist for an article on qualitative research *

\author{
Department of \\ Sexually Transmitted \\ Diseases, UCL \\ Medical School, \\ Mortimer Market \\ Centre, London \\ WC1E 6AU \\ K A Fenton \\ R Power \\ Correspondence to: \\ Dr Kevin Fenton. \\ Accepted for publication \\ 19 August 1997
}

(1) Did the article describe an important clinical problem addressed via a clearly formulated question?

(2) Was a qualitative approach appropriate?

(3) Was the sampling strategy clearly defined and justified? In particular

(a) Has the method of sampling for both subjects and the setting been adequately defined?

(b) Have the investigators studied the most useful or productive range of individuals and settings relevant to their question?

(c) Have the characteristics of the subjects been defined?

(4) What was the researcher's perspective and has the researcher critically examined his or her own role, potential bias, and influence?

(5) What methods did the researcher use for collecting data? In particular

(a) Have appropriate data sources been studied?

(b) Have the methods used for data collection been described in enough detail?

(c) Was more than one method of data collection used?

(d) Were the methods used reliable and independently verifiable (for example, audiotape, videotape, field notes)?

(e) Were observations taken in a range of circumstances (for example, at different times)

(6) What methods did the researcher use to analyse the data and what quality control measures were implemented?

(7) What are the results and do they address the research question?

(8) Are the results credible?

(9) What conclusions were drawn, and are they justified by the results?

(10) To what extent are the findings of the study transferable to other clinical settings? 
of homosexual men have not consistently adopted safe sex practices and that unsafe sexual behaviour and HIV transmission are again increasing. ${ }^{4-6}$ Unprotected anal sex is considerably more likely to occur in the context of a regular, rather than a casual or less established, relationship, ${ }^{78}$ and although many men have restricted unprotected anal intercourse to partners of the same HIV status, this concordance is often perceived, not proved. Unsurprisingly, significant HIV transmission currently occurs within existing relationships. ${ }^{9}$

Estimates of the prevalence of unprotected anal intercourse (UPAI) among homosexual men vary enormously. One London based survey, ${ }^{10}$ in which 553 homosexual men were sampled from a variety of commercial venues, suggested that over a third (35\%) had UPAI in the previous year. Nearly a fifth (19\%) of the sample had UPAI with one or more partners of unknown and/or discordant HIV status. Results from another survey have also suggested similar levels of UPAI. ${ }^{11}$ Quantitative research has identified a number of predictors of relapse to unprotected sex, including unavailability or less positive attitudes towards use of condoms, not being involved in a primary relationship, use of recreational drugs and alcohol, sexual arousal, degree of emotional involvement and perceptions of risk, HIV concordant status, and being in love..$^{12}$ Other social and psychological correlates include conflicting beliefs, feelings and desires about sex, personal history of child sexual abuse, poor sexual communication skills, personal efficacy regarding condom use, and avoidance of anogenital intercourse. ${ }^{14}$

The importance of unprotected sexual intercourse between homosexual men in potentiating the HIV epidemic was highlighted in the paper under discussion. The authors argue that the focus of many epidemiological and behavioural studies has been the identification of the demographic, attitudinal and behavioural correlates of unprotected sex, and that less attention has been given to systematically studying how homosexual men themselves explain unprotected intercourse. They therefore aimed to explore "accounts" of unprotected sexual intercourse, not as real motives of behaviour, but as a resource to illuminate the knowledge, assumptions, and values that inform behaviour.

\section{Was a qualitative approach appropriate?}

The study under review was undertaken to explore the explanations given by a sample of homosexual men in England of specific occasions in which they had unprotected intercourse. Two qualitative studies exploring these issues were discussed by the authors. Prieur $^{15}$ argued that anal intercourse without a condom was central to emotional relationships among homosexual men and, for that reason, difficult to alter. Levine and Siegel ${ }^{16}$ related the reasons given for unprotected intercourse to folk constructions of the risk of HIV infection, and the culturally available motives for "improper sex".
A qualitative approach was therefore appropriate to gain a greater understanding of the meanings, considerations, and constraints surrounding high risk sexual behaviour, and to explore ways of developing more relevant health education interventions. This approach was also an appropriate method for providing information on the context in which unsafe sex occurs among homosexual men, and to complement previous quantitative research findings.

\section{Was the sampling strategy clearly defined and justified?}

Has the method of sampling (for both the subjects and the setting) been described and have the investigators studied the most useful or productive range of individuals and settings relevant to their question? The characteristics of the subjects should also be defined.

The qualitative interviews were undertaken with a subset of homosexual men $(n=150)$ recruited to a large cross sectional study of homosexual men's sexual behaviour changes in relation to HIV/AIDS. ${ }^{17}$ In the main study, men were sampled from a variety of venues including genitourinary medicine clinics, "gay" organisations, clubs, pubs, and by snowball sampling in London, Manchester, the Midlands, and Bristol. Details were not given on the methods used to sample the 150 men for qualitative interviews. For example, we are not told if participants were randomly selected from the main sample or whether a purposive sampling strategy (whereby respondents were sampled based on specific predetermined criteria in order to cover a range of constituencies-for example, different age, social class, and cultural backgrounds) was used.

As with quantitative research, proper attention should be given to the method(s) used for sampling respondents, as this will ultimately influence the validity of results and the degree to which research findings can be generalised. Other strategies-for example, "convenience" sampling (using "gay" venues), theoretical sampling (where the researchers initially select informants, analyse the data, and then decide which further data to collect and from whom), and snowball sampling (using social networks) are often used to locate hard to reach groups.

In all, 113 men (75\%) reported having UPAI in the past 5 years and were eligible to participate in the study; 94 men (83\%) agreed to take part in a taped interview. Sixteen respondents were subsequently excluded from the final analysis-seven (6\%) because of mechanical (tape recording) problems, and nine $(8 \%)$ who had used condoms which broke or came off during intercourse. No further data were provided on the demographic or behavioural risk characteristics of the respondents who were included or excluded. Thus, based on the information provided, we can only conclude that the subsample used in the study was relevant in terms of their recent history of UPAI. 
What was the researcher's perspective and has the researcher critically examined his or her own role, potential bias, and influence?

Respondents were asked to take part in a more open ended interview to explore, in qualitative terms, the issues surrounding UPAI. In addition to the precoded questions in the main questionnaire, these men were asked to elaborate on their reasons for not using a condom on the last occasion in which they had had UPAI. The researchers state that "non-leading prompts and supplementary questions were used to elicit as detailed explanations as possible".

Since men recruited to this study reported UPAI within the past 5 years, recall bias could result in the more traumatic or eventful episodes being preferentially reported. Alternatively, men may be more likely to report episodes of UPAI which occurred with casual partners (high risk, less acceptable) than those with regular partners (lower risk, possibly more acceptable) or vice versa. In the paper's discussion, the authors admit that it is often difficult to eliminate systematic or recall biases when retrospective information in accounts are used, especially when they concern motives and feelings at the time. This is made worse when the subject being discussed is normatively disapproved of (for example, UPAI). The researchers used two strategies to overcome this. Firstly, interviews were conducted by an interviewer who had been trained to avoid as many as possible of these sources of bias. Secondly, the researchers were willing to interpret their findings with caution: "modest objectives" were set for the interpretation of data generated in this context, the primary concern being to elicit culturally available meanings and the relevant considerations for men in relation to unsafe sex.

\section{What methods did the researcher use for collecting data?}

Have appropriate data sources been studied? Have the methods for data collection been described in enough detail? Was more than one data collection method used? Were the methods used reliable and independently verifiable (for example, field notes, audiotape, videotape) and, finally, were the observations taken in a range of circumstances (for example, at different times)?

As mentioned previously, the subsample of homosexual men asked to participate in this study was derived from a large sample of homosexual men drawn from a variety of sources and of varying socioeconomic backgrounds. Data were obtained both from the questionnaire (which provided demographic and risk behaviours) and through tape recorded in-depth interviews. No information was given regarding the topics covered in the in-depth interviews. For example, were respondents only asked to recall their last episode of UPAI? Did the interviewers collect other contextual information (for example, cultural issues, respondent's social or sexual background) during the interviews, and if so how was this eventually used?

The authors mentioned a number of practical difficulties which occurred during recruitment and interviewing. Some eligible respondents were lost because they were reluctant to be tape recorded or interviews were discarded because of difficulties with operating the tape recorders. Seventy eight transcripts were included in the analysis. No information was given about the characteristics of those respondents whose interviews were lost and whether they differed in any way from those who were included in the final analysis.

Information about the circumstances in which the interviews were undertaken was not mentioned in the paper. Were respondents interviewed at home or at social venues? When was it undertaken? Who interviewed them and what were the characteristics of the interviewers? Response rates and participation in studies covering sensitive or private issues may vary according to the interviewer's sex, age group, and perceived sexuality. Once again this contextual information is important to obtain a clearer idea of the circumstances surrounding the interview and will influence how confident we can be that the data collected are robust.

What methods did the researcher use to analyse the data and what quality control measures were implemented?

How were themes and concepts derived from the data. Did more than one researcher perform the analysis and what method was used to resolve differences in interpretation? Also were negative or discrepant results fully addressed or just ignored?

The researchers sought to analyse the explanations given by a sample of homosexual men for the most recent occasion on which they had engaged in UPAI. The researchers used an approach based on sociological analysis of the language of motives as "accounts" and they provided some explanation and references concerning this method. The accounts provided by respondents are not viewed as exact descriptions of the "real" motives for behaviour, but are seen as a powerful resource that can illuminate the knowledge, assump tion, and values that inform behaviour. Accounts are viewed as socially patterned justifications and versions of personal behaviour that are inevitably retrospective. They, therefore, do not correspond with motivations governing behaviour, nor are they used as post hoc realisations.

Having more than one researcher independently to assess transcripts and compare agreement between researchers is one way to test the reliability of data analysis. Other methods include maintaining meticulous records of interviews and observations, documenting the analysis process in detail, deciding on interpretive procedures before the analysis, and double coding of interviews. In this paper, we do not know how many researchers performed the analysis and although discrepant results were noted (three men gave accounts which could not be classified into any category) they were 
not discussed in detail. Additionally, the authors made no reference to using any particular code and retrieval methods of data analysis (for example, NUDIST, ATLAS computer programs) nor do they refer to any theoretical framework, such as grounded theory.

\section{What are the results and do they address the research question?}

Four distinct types of accounts were offered by men to describe the circumstances and motivations surrounding their last episode of anal intercourse without a condom (see table 2).

\section{EMOTIONAL NEEDS AND DRIVES}

The power of fundamental needs and drives was given as an explanation for UPAI. These needs and drives were presented as intense and compelling and when they were aroused, meeting them was all that mattered. Facets of these accounts included the need to express love and intimacy, to heighten the expression of mutual commitment, the power of sexual desires or sexual satisfaction between partners.

\section{THE CALCULUS OF RISK}

In this type of account respondents set out the factors which they considered to be a part of a conscious calculation of the risks involved in UPAI. In this context, the calculus was eventually taken as grounds for concluding that there was virtually no risk of HIV transmission in the encounter and therefore it was "not necessary" to use condoms. Common beliefs included the conviction that neither they nor their partner were infected, that using their partner's sexual history could support the view that he was not infected, that their partner's current patterns of behaviour and personal qualities indicated little or no risk.

\section{CONDOMS AND TRUST}

In the context of a regular relationship, suggesting that a condom should be used could be taken as implying that the interviewee thought that either he or his partner could be HIV positive. Alternatively, in a relationship which is mutually monogamous, using condoms may implicitly suggest unprotected sex with someone else. Hence, some men argued that the stigma associated with condom use and the social pressures against them made it impossible for them to do so.

LAPSES OF CONTROL

Participants described situations in which their usual control over their sexual behaviour lapsed. Blame was then apportioned to external factors-for example, drugs and alcohol, grief and emotional distress, or their partner. Often these lapses were viewed with considerable regret and with hindsight deemed as "foolish" or "silly".

These results directly address the research question in that they describe categories related to accounts of UPAI. Again, additional information on the context and circumstance would have greatly added to these findings, and enabled the reader to determine whether there were other important issues to be explored in the data. For example, was there a cultural dimension to these findings? How did the accounts vary between young and older homosexual men? Did the loss of a lover or friend to AIDS have any impact on the accounts provided? We know that having a current regular partner was an important determinant in at least one account, but were there other factors which could have been explored?

Table 2 Summary of results: descriptions of homosexual men's accounts of unsafe sex

\begin{tabular}{|c|c|}
\hline Account category & Description \\
\hline $\begin{array}{l}\text { Emotional needs and drives } \\
\text { Reported as a primary account by } \\
21(27 \%) \text { men }\end{array}$ & $\begin{array}{l}\text { Needs and drives presented as intense and compelling; when aroused, meeting } \\
\text { them was all that mattered. Includes } \\
\text { (i) The need to express love and intimacy (especially with regular partner) } \\
\text { (ii) The risks involved can heighten the expression of UPAI as an expression of } \\
\text { (iii) The power of sexual desires which "took them over" (especially with non- } \\
\text { (iv) Sexual satisfaction being the sole consideration }\end{array}$ \\
\hline $\begin{array}{l}\text { Calculus of risk } \\
\text { Reported as a primary account by } \\
31(40 \%) \text { men }\end{array}$ & $\begin{array}{l}\text { Participants set out the factors that they considered in a conscious calculation of } \\
\text { the risks involved in UPAI. They were all taken as grounds for concluding that } \\
\text { there was virtually no risk of HIV transmission in the encounter and therefore } \\
\text { unnecessary to use condoms. Evidence to support their belief included } \\
\text { (i) Partner(s) had negative HIV test } \\
\text { (ii) Knowledge of aspects of partner's sexual history to support view that he was not } \\
\text { (iii) History of sexual contact with women seen as being "protective" } \\
\text { (iv) Personal qualities of the partner for example ("he's not the sort of person") } \\
\text { (v) Situational factors that their partner was not a "risky" person }\end{array}$ \\
\hline $\begin{array}{l}\text { Condoms and trust } \\
\text { Reported as a primary account by } \\
11(14 \%) \text { men }\end{array}$ & $\begin{array}{l}\text { The stigma associated with condom use and the social pressures against suggesting } \\
\text { them made it impossible to do so. In the context of regular relationships, } \\
\text { suggesting a condom for UPAI could imply } \\
\text { (i) That the respondent thought his partner could be HIV positive } \\
\text { (ii) That UPAI could be occurring with someone else }\end{array}$ \\
\hline $\begin{array}{l}\text { Lapses of control } \\
\text { Reported as a primary account by } \\
12(15 \%) \text { men }\end{array}$ & $\begin{array}{l}\text { Situations in which respondents' usual control over sexual behaviour "lapsed" } \\
\text { Although acknowledging their own error or fault in having potentially risky sex, } \\
\text { various mitigating circumstances were given to reduce the element of personal } \\
\text { blame.Thus, responsibility was denied by } \\
\text { (i) Appealing to the effects of alcohol or drugs } \\
\text { (ii) Blaming grief and emotional distress following the break up of a significant } \\
\text { (iii) Blaming their partner for UPAI }\end{array}$ \\
\hline
\end{tabular}


Are the results credible?

For example, are the explanations presented plausible and coherent? Have sequences from the original data been included in the paper (for example, direct quotation)? Is it possible to determine the source of the data presented (for example, by numbering of extracts)? How much information collected is available for independent assessment?

The explanations given were plausible and coherent in so far as the objectives were concerned. In the presentation of results, original data (excerpts from interviews) were used to illustrate the accounts. It was not possible to determine the precise source of the data as the extracts were not labelled. Twenty eight men gave accounts which drew on more than one category, though they generally gave one primary account and supplemented it with subsidiary accounts of other types. The authors reported the number of men reporting each account as a primary category (see table 2 ). In general, enough data were provided in the excerpts to illustrate the main categories and subcategories identified without compromising respondents' confidentiality-a concern when reporting qualitative findings. The descriptive accounts therefore appeared to be grounded in the original data, and we can assume that this could be reviewed and assessed independently by recourse to archived research material.

However, no information is provided regarding the availability of data for independent assessment. In some cases, a full transcript of the raw qualitative research data could be made available to the reader on microfilm or computer disks, ${ }^{18}$ although this may be cumbersome. Another partial solution is to present extensive sequences from the original data, followed by a detailed summary..$^{19}$ Additional methods of data validation include feeding back research findings to respondents to see whether they gave a reasonable interpretation of their experiences. ${ }^{20}$ Alternatively, comparing results with evidence from other research findings could be undertaken. ${ }^{21}$

\section{What conclusions were drawn, and are} they justified by the results?

In particular have alternative explanations for results been explored and discounted?

If alternative explanations were discussed and subsequently discounted by the researchers, they were not recorded in this paper. They concluded, however, that the discussion of the types of accounts illustrated in this study could be used to raise individuals' awareness of the constraints against practising safer sex in sexual encounters. This awareness may then be important in reinforcing alternative, safer responses to subsequent sexual encounters. The authors also emphasised the implications of their findings for health promotion. Firstly, they assert that health education cannot by itself promote safer sex as homosexual men are already fully aware of its importance. Secondly, they note that these accounts provide evidence of sequences of actions and perceptions that can be anticipated and addressed by developing more relevant interventions. Thirdly, they suggest that recognition and discussion of the accounts associated with unsafe sex should be used to influence how homosexual men learn and feel about sex and in so doing empower them in negotiating safer sex.

\section{To what extent are the findings of the study transferable to other clinical settings?}

Were the subjects in the study similar in important respects to your own patients? Is the context similar to your own practice?

Many qualitative studies are undertaken outside of the clinical setting and direct comparison or transferability of findings may not be possible. The research findings can, however, provide a contextual or explanatory dimension to clinical problems which can influence our understanding, behaviours, and attitudes and usefully inform clinical decision making. Apart from the results, one should also consider whether the research methodology is applicable and transferable to the clinical setting. For example, studies exploring accounts of behaviours could be duplicated to better understand compliance with therapy, partner notification, or HIV testing behaviours.

Although limited information on the study subjects was provided, the homosexual men participating in this qualitative study were a subsample of men selected from a wide variety of social, commercial, and medical venues. Previous studies have suggested that homosexual men attending genitourinary medicine clinics and using the commercial "gay scene" may have higher risk profiles than others. The findings from this study are therefore highly relevant and applicable to clinical settings, such as genitourinary medicine clinic populations.

\section{Conclusions}

We have used this study of homosexual men's accounts of unsafe sex to illustrate the poten tial to critically review a qualitative research article. The checklist of criteria provided a framework for systematic critique. Other potential assessment criteria include:

(1) Ensuring that adequate contextual information about interviews and respondents is provided. This includes details on the setting, personal or cultural background, and interpersonal issues-for example, relationships, social networks. This will allow readers to determine similarities and differences between the case studies and other settings of the same type.

(2) Reference to prior body of knowledge. How do the research findings contribute to and fit in with existing knowledge (social theory or other empirical work)? This allows readers to make the best use of the research material

(3) Use of theory/grounded theory, where 
research findings are presented in a manner such that they would be recognisable to the respondents (by, for example, recording their words, ideas, and actions) while at the same time being more structured and self consciously explanatory than anything that the participants would themselves produce.

As in quantitative research, the basic strategy to guarantee rigour in qualitative research is through systematic and explicit research design, data collection, interpretation, and communication. Consequently, in reviewing the findings of such research we must ascertain that the methods used are appropriate, transparent, and the results credible.

Finally, we need to satisfy ourselves that the conclusions are firmly grounded in the data and where possible, reliability and validity checks have been incorporated into the research design. As with all applied research, be it qualitative or quantitative, we would wish to see the relevance to clinical practice of service intervention stressed. By submitting itself to rigorous critical review, qualitative research will continue to improve and consolidate its methodological robustness, while maintaining its flexibility and original perspective.

1 Boulton M, McLean J, Fitzpatrick R, Hart G. Gay men's

2 Hunt AJ, Weatherburn P, Hickson FCI, Davies PM, McManus TJ, Coxon APM. Changes in condom use in gay men. AIDS Care 1993;5:439-48.

3 Kippax S, Crawford J, Davis M, Rodden P, Dowsett G Sustaining safe sex: a longitudinal study of a sample of homosexual men. AIDS 1993;7:257-63.

4 Evans BG, Catchpole MA, Heptonstall J, Mortimer JY McCarrigle, Nicoll AG, et al. Sexually transmitted diseases and HIV-1 infection among homosexual men in England and Wales. BMF 1993;306:426-8.

5 De Wit J, van Griensven G. Time from safe to unsafe sexual behaviour among homosexual men. AIDS 1994;8:123-6.

6 Van den Hoek JAR, van Griensven GJP, Coutinho RA.
Increase in unsafe homosexual behaviour. Lancet 1990; 336:179-80.

7 Fitzpatrick R, Dawson J, Boulton M, McLean J, Hart G. Social psychological factors that may predict high risk sexual behaviour in gay men. Health Education fournal 1991;50:63-6.

8 Schechter MT, Carib KJ, Willoughby B, Douglas B McLeod WA, Maynard M, et al. Patterns of sexua behaviour and condom use in a cohort of homosexua men. Am F Public Health 1988;78:1535-8.

9 Hart GJ, Dawson J, Fitzpatrick R, Boulton M, McLean J, Brookes $\mathrm{M}$, et al. Risk behaviour, anti-HIV and antihepatitis B core prevalence in clinic and non-clinic samples of gay men in England, 1991-92. AIDS 1993;7: ples of

10 Nardone A, Mercey DE, Johnson AM. Surveillance of sexual behaviour among homosexual men in a central London health authority. Genitourin Med 1997;73 198-202.

11 Hickson FCI, Reid DS, Davies PM, Weatherburn P, Beardsell S, Keogh PG, et al. No aggregate change in homosexual risk behaviour among gay men attending the Gay Pride festivals, United Kingdom 1993-95. AIDS 1996;10:771-4.

12 Stall R, Ekstrand M, Pollack L, McKusick L, Coates TJ Relapse from safer sex: the next challenge for AIDS prevention efforts. F AIDS 1990;3:1181-7.

13 Doll IS, Byers RH, Bolan G, Douglas JM Jr, Moss PM, Weller PD, et al. Homosexual men who engage in highrisk sexual behaviour. A multi-centre comparison. Sex risk sexual behaviour. A

14 de Wit JBF, van Griensven GJP, Kok G, Sandfort TGM Why do homosexual men relapse into unsafe sex? Predictors of resumption of unprotected anogenital intercourse with casual partners. AIDS 1993;7:1113-8.

15 Prieur A. Gay men: reasons for continued practice of unsafe sex. AIDS Educ Prevent 1990;2:110-7.

16 Levine M, Siegel K. Unprotected sex: understanding gay men's participation. In: Huber J, Schneider B, eds. The social context of AIDS. London: Sage Publications, 1992: $47-71$.

17 McLean J, Boulton M, Brookes M, Lakhani D, Fitzpatrick $\mathrm{R}$, Dawson J, et al. Regular partners and risky behaviour: why do gay men have unprotected intercourse? AIDS Why do gay men have

18 Waitzkin $\mathrm{H}$. On studying the discourse of medical encounters: a critique of quantitative and qualitative methods and a proposal for reasonable compromise. Med Car 1990;28:473-88

19 Mays N, Pope C. Rigour and qualitative research. $B M f$ 1995;311:109-12.

20 McKeganey NP, Bloor MJ. On the retrieval of sociological descriptions: respondent validation and the critical case of ethnomethodology. Int $\mathcal{f}$ Social Policies 1990;19: 169-90.

21 Britten N. Qualitative interviews in medical research. BMF 1995;311:251-3. 